\title{
PENGARUH TERAPI MUSIK KLASIK JAWA TERHADAP PENURUNAN TEKANAN DARAH PADA LANSIA HIPERTENSI DI UPT PANTI WERDHA MOJOPAHIT MOJOKERTO
}

\section{The Effect Of Java Classical Music Therapy To The Decrease Of Blood Pressure For Hypertensive Elderly People At UPT Panti Werdha Mojopahit, Mojokerto}

\author{
Muhammad Fadhil Hidayat ${ }^{1)}$ Pepin Nahariani $^{2)}$, Alik Septian Mubarrok ${ }^{3)}$ \\ ${ }^{1,2,3}$ Program Study S1 Keperawatan STIKES Pemkab Jombang \\ Email : mfadhilhidayat@yahoo.com
}

\begin{abstract}
ABSTRAK
Proses penuaan menimbulkan berbagai masalah pada lansia salah satunya adalah stress. Salah satu penyakit yang berhubungan dengan stres adalahhipertensi. Berdasarkan data Dinas Kesehatan Jombang, penderita hipertensi di Jombang pada tahun 2016 berjumlah 41.453 orang dan menduduki peringkat 3 dari 10 penyakit tertinggi di Jombang. Tujuan dari penelitan ini adalah untuk mengetahui pengaruh terapi musik klasik jawa terhadap penurunan tekanan darah pada lansia hipertensi diUPT Panti Werdha Mojopahit Mojokerto.

Rancangan penelitian menggunakan Pre Eksperiment Design denganrancangan One Group PretestPostest Design. Populasi pada penelitian ini adalah lansia yang berada di UPT Panti Werdha Mojopahit Mojokerto sebanyak 30 orang. Sampel diambil dari lansia yang tinggal di UPT Panti Werdha Mojopahit Mojokerto dengan metode teknik total sampling, berjumlah 26 orang lansia.Analisa data menggunakan uji statistik Paired T-Test.

Hasil penelitian menunjukkanmean sistol Pre-test $153 \mathrm{mmHg}$ dan Post-test $146 \mathrm{mmHg}$ dengan $\mathrm{p}$ value systole $=0,001(\mathrm{p}<0,05)$ dan mean diastole Pre-test $101 \mathrm{mmHg}$ dan Post-test $97 \mathrm{mmHg}$ dengan $\mathrm{p}$ value diastole $=0,002(\mathrm{p}<0,05)$ yang artinya ada pengaruh terapi musik klasik jawa terhadap penurunan tekanan darah pada lansia hipertensi diUPT Panti Werdha Mojopahit Mojokerto. Pada saat diberikan terapi musik seseorang menjadi rileks dan tenang, otak akan memproduksi hormon serotonindan endorfin yang menyebabkan seseorang merasa tenang dan nyaman.

Penelitian ini dapat digunakan sebagai bahan masukan bagi lansia hipertensi di UPT Panti Werdha Mojopahit Mojokerto sebagai pilihan dari salah satu penanganan non-farmakologihipertensi.
\end{abstract}

Kata kunci : Terapi musik klasik jawa, tekanan darah, lansia.

\begin{abstract}
The aging process raises various problems for elderly people, one of them is stress, one of diseases that associates with stress is hypertension. Based on data from the Health Department Office of Jombang, hypertension sufferers in Jombang in 2016 reached to 41,453 people and it was ranked 3 of 10 the highest diseases in Jombang. This research aimed to determine the effect of Javanese classical music therapy to the decrease of blood pressure for hypertensive elderly people at UPT Panti Werdha Mojopahit Mojokerto.

The research design used Pre Experiment Design with One Group Pre test-Pos test Design. The population in this research was elderly people who are at UPT Panti Werdha Mojopahit, Mojokerto as many as 30 people. Samples were taken from elderly people who lived at UPT Panti Werdha Mojopahit ,Mojokerto with the method of total sampling technique, as many as 26 elderly people .Data analysis used the statistical test of Paired T-Test.

The result of research showed that systolic mean pre-test was $153 \mathrm{mmHg}$ and Post-test was 146 $\mathrm{mmHg}$ with $\mathrm{p}$ value systolic $=0.001(\mathrm{p}<0.05)$ and Diastolic mean pre-test was $101 \mathrm{mmHg}$ and Post-test was $97 \mathrm{mmHg}$ with $\mathrm{p}$ value diastolic $=0.002(\mathrm{p}<0,05)$ which meant there was the effect of Javanese classical music therapy to the decrease of blood pressure for hypertensive elderly people at UPT Panti Werdha Mojopahit, Mojokerto. When someone was given music therapy, he became relaxed and peaceful, the brain would produce serotonin and endorphin hormones that caused a person to feel calm and comfortable.

This research can be used as input material for hypertensive elderly people at UPT Panti Werdha Mojopahit, Mojokert it is as a choice that becomes one way for handling non-pharmacology hypertension.
\end{abstract}

Keywords: Javanese classical music therapy, blood pressure, elderly people. 


\section{PENDAHULUAN}

Hipertensi merupakan masalah yang sedang dialami oleh seluruh dunia. Hipertensi merupakan faktor risiko utama terjadinya kematian. setiap tahun hipertensi menjadi penyebab 1 dari setiap 7 kematian (7 juta per tahun) disamping menyebabkan kerusakan jantung, otak dan ginjal. Tekanan darah yang tinggi juga merupakan faktor resiko penyebab terjadinya penyakit kardiovaskuler, yang dapat meningkatkan morbiditas dan mortalitas penyakit kardiovaskuler. Oleh karena itu, penyakit hipertensi harus dapat dicegah dan diobati serta dikendalikan dengan baik. Hipertensi masih menjadi masalah kesehatan pada kelompok lansia. Hal ini akibat dari perubahan gaya hidup yang modern, stress juga dapat mengakibatkan peningkatan tekanan darah pada lansia. Terdapat beberapa jenis penyakit yang berhubungan dengan stres yang dialami seseorang, di antaranya hipertensi (Finda, 2012). Oleh karena itu stress pada lansia patut diperhatikan. Dengan terapi yang tepat akan dapat mengatasi hipertensi. Terapi musik merupakan terapi non-farmakologi yang efektif untuk mengatasi stress.

World Health Organization (WHO, 2013) memperkirakan sekitar 1 milyar penduduk di dunia menderita penyakit hipertensi dan diprediksi pada tahun 2025 ada sekitar $29 \%$ jiwa di dunia yang akan menderita penyakit hipertensi. Di Indonesia terjadi peningkatan prevalensi hipertensi. Secara keseluruhan prevalensi hipertensi di Indonesia tahun 2013 sebesar 26,5\%. Sedangkan prevalensi penyakit ini di Propinsi Jawa Timur sebesar 26,2\% masih melebihi prevalensi nasional (Kemenkes RI., 2013). Berdasarkan data dari Dinas Kesehatan Jombang, penderita hipertensi di Jombang pada tahun 2016 menunjukkan kejadian hipertensi berjumlah 41.453 orang dan menduduki peringkat 3 dari 10 penyakit tertinggi yang ditemukan di Kabupaten Jombang. (Dinas kesehatan Jombang, 2016).

Bertambahnya usia pada lansia membuat perubahan struktural dan fungsional dalam tubuh dan salah satunya mengalami kerusakan struktural dan fungsional aorta, yaitu arteri yang mengalirkan darah dari jantung mengalami pengerasan sehingga membuat tekanan darah semakin tinggi dan menyebabkan lansia mengalami hipertensi. Banyak faktor yang merupakan pemicu terjadinya hipertensi. Berdasarkan hasil penelitian Finda (2012), menyimpulkan bahwa ada hubungan antara kejadian hipertensi dengan stres. Untuk menangani hipertensi maka perlu mendapatkan terapi hipertensi yang bertujuan mencegah komplikasi, sehingga dapat menurunkan kejadian penyakit kardiovaskular. Terapi musik membantu orang-orang yang memiliki masalah emosional dalam mengeluarkan perasaan mereka, membuat perubahan positif dengan suasana hati, membantu memecahkan masalah, dan memperbaiki konflik pribadi (IHA, 2010).

Pengobatan non-farmakologi hipertensi bisa dengan mengubah gaya hidup yaitu mengurangi stress dan melakukan diet dalam asupan makan misalnya mengurangi asupan garam memperbanyak serat dengan cara makan buah dan sayuran serta mengurangi kebiasaan buruk seperti merokok dan menkonsumsi alkohol. Namun pengobatan non-farmakologi tidak hanya itu, bisa juga dengan menggunakan terapi musik klasik jawa. Terapi musik klasik jawa merupakan terapi yang tepat untuk mencegah menurunkan tekanan darah, selain itu tekniknya sangat mudah dilakukan dan terjangkau untuk mengurangi tekanan darah.

Para peneliti dari the neuro, melalui MRI scan membuktikan bahwa otak melepas zat dopamin (hormon yang terkait dengan sistem otak, memberikan perasaan kenikmatan dan penguatan untuk memotifasi seseorang secara proaktif melakukan kegiatan tertentu) saat melakukan terapi musik dalam kapasitas yang tidak berlebihan (Natalina, 2013).

Dalam memberikan terapi musik, terdapat beberapa hal yang harus diperhatikan, salah satunya adalah jenis musik yang akan diberikan. Ketika mendengar suara musik yang indah maka hormon "kebahagiaan" (betaendorfin) akan berproduksi (Natalina, 2013 ). Terdapat beberapa jenis musik, misalnya musik klasik, musik rock, musik gamelan, musik jawa dan lain-lain. Musik klasik jawa adalah salah satu jenis musik klasik yang sesuai dengan lansia. Kebanyakan lansia mengaku lebih menyukai 
musik-musik tradisional, misalnya musik klasik Jawa.

Terapi musik klasik jawa merupakan teknik yang efektif untuk mengurangi tekanan darah menunjukkan betapa besar dalam mempengaruhi kondisi rileks pada diri seseorang, karena dapat merangsang pengeluaran endorphine dan serotonin, yaitu sejenis morfin alami tubuh dan juga metanonin sehingga kita bisa merasa lebih relaks pada tubuh seseorang yang mengalami stres (Mucci, 2002).

Berdasarkan uraian diatas peneliti tertarik untuk melakukan penelitian tentang pengaruh terapi musik klasik jawa terhadap penurunan tekanan darah pada lansia hipertensi di UPT Panti Werdha Mojopahit Mojokerto. Dalam hal ini peneliti memberikan intervensi terapi musik klasik jawa untuk membantu menurunkan tekanan darah pada lansia hipertensi di UPT Panti Werdha Mojopahit Mojokerto.

\section{METODE}

Rancangan yang digunakan dalam penelitian ini adalah rancangan penelitian pra-eksperimental design dengan menggunakan rancangan One-Group PraPost test Design yaitu kelompok subjek di observasi sebelum dilakukan intervensi, kemudian di observasi lagi setelah intervensi
(Nursalam, 2014). Populasi dalam penelitian ini adalah lansia yang berusia 60-80 tahun dengan jumlah 30 Lansia di UPT Panti Werdha Mojopahit Mojokerto.

Sampel yang digunakan dalam penelitian ini adalah lansia hipertensi yang berada di Panti Werdha Mojopahit Mojokerto Tahun 2017 yang berjumlah 30 orang. Teknik sampling yang digunakan dalam penelitian ini adalah total sampling.

Dalam pelaksanaan penelitian ini, peneliti mengukur tekanan darah responden sebanyak dua kali, yakni sebelum dilakukan terapi musik klasik jawa dan setelah dilakukan terapi musik klasik jawa, kemudian peneliti membandingkan antara tekanan darah sebelum dan sesudah diberikan terapi.

Terapi musik klasik jawa di berikan selama 1 minggu setiap hari pukul $10.00 \mathrm{di}$ Aula sesuai dengan Satuan Operasional Prosedur (SOP). Responden dikumpulkan dalam satu tempat kemudian di lakukan pengukuran tekanan darah kepada seluruh responden. Setelah itu musik diputarkan kurang lebih selama 30 menit, kemudian dilakukan pengukuran tekanan darah kembali. Proses terapi dibimbing langsung oleh peneliti dan dilaksanakan selama 1 minggu.

HASIL

Tabel 1 Distribusi karakteristik tekanan darah responden sebelum diberikan terapi musik klasik jawa.

\begin{tabular}{lllll}
\hline \multirow{2}{*}{$\begin{array}{l}\text { Tekanan Darah } \\
\text { (systole dan diastole) }\end{array}$} & \multicolumn{3}{l}{ Pre- Test } \\
\cline { 2 - 6 } & \multicolumn{2}{l}{ Systole } & \multicolumn{2}{l}{ Diastole } \\
\cline { 2 - 6 } & F & $\%$ & F & \% \\
\hline $140-149 / 90-99$ & 5 & 19,2 & 7 & 26,9 \\
$150-159 / 100-109$ & 9 & 34,6 & 11 & 42,3 \\
$160-169 / 110-119$ & 10 & 38,5 & 7 & 26,9 \\
$170-179 / 120-129$ & 2 & 7,7 & 1 & 3,8 \\
\hline Total & 26 & 100 & 26 & 100 \\
\hline
\end{tabular}

Sumber : Data Primer 2017

Berdasarkan tabel diatas menunjukkan bahwa tekanan darah responden pre-test dengan systole 10 responden $(38,5 \%)$ dan diastole 11 responden $(42,3 \%)$ hampir setengahnya mengalami tekanan darah 160/100 $\mathrm{mmHg}$. 
Tabel 2 Distribusi karakteristik tekanan darah responden sesudah diberikan terapi musik klasik jawa.

\begin{tabular}{|c|c|c|c|c|}
\hline \multirow{3}{*}{$\begin{array}{l}\text { Tekanan Darah } \\
\text { (systole dan diastole) }\end{array}$} & \multicolumn{4}{|c|}{ Post- Test } \\
\hline & \multicolumn{2}{|c|}{ Systole } & \multicolumn{2}{|c|}{ Diastole } \\
\hline & $\mathbf{F}$ & $\%$ & $\mathbf{F}$ & $\%$ \\
\hline $140-149 / 90-99$ & 14 & 53,8 & 12 & 46,2 \\
\hline $150-159 / 100-109$ & 9 & 34,6 & 11 & 42,3 \\
\hline $160-169 / 110-119$ & 3 & 11,5 & 2 & 7,7 \\
\hline $170-179 / 120-129$ & 0 & 0 & 1 & 3,8 \\
\hline Total & 26 & 100 & 26 & 100 \\
\hline
\end{tabular}

Sumber : Data Primer 2017

Berdasarkan tabel diatas menunjukkan bahwa tekanan darah responden post test yaitu systole 14 responden $(53,8 \%)$ dan diastole 12 responden $(46,2 \%)$ hampir setengahnya mempunyai tekanan darah $140 / 90 \mathrm{mmHg}$

Tabel 3 Distribusi frekuensi perubahan tekanan darah pada lansia dengan hipertensi sesudah diberikan terapi musik klasik jawa di UPT Panti Werdha Mojopahit Mojokerto pada bulan April 2017.

\begin{tabular}{|c|c|c|c|c|c|}
\hline \multirow{3}{*}{$\begin{array}{l}\mathbf{N} \\
\mathbf{0}\end{array}$} & \multirow{3}{*}{ Tekanan darah (mmHg) } & \multicolumn{3}{|c|}{$\begin{array}{l}\text { Perubahan Tekanan Darah } \\
\text { musik klasik jawa }\end{array}$} & sesudah terapi \\
\hline & & \multicolumn{2}{|c|}{$\begin{array}{c}\text { Systole } \\
\text { Post-test }\end{array}$} & \multicolumn{2}{|c|}{$\begin{array}{r}\text { Diastole } \\
\text { Post-test }\end{array}$} \\
\hline & & $\mathbf{F}$ & $\%$ & $\mathbf{F}$ & $\%$ \\
\hline 1. & Meningkat & 3 & 11,5 & 1 & 3,8 \\
\hline 2. & Menurun & 17 & 65,4 & 11 & 42,3 \\
\hline 3. & Tetap & 6 & 23,1 & 14 & 53,8 \\
\hline \multicolumn{2}{|c|}{ Jumlah } & 26 & 100 & 26 & 100 \\
\hline
\end{tabular}

Sumber : Data Primer 2017

Berdasarkan tabel diatas menunjukkan bahwa tekanan darah systole post-test yaitu 17 responden $(65,4 \%)$ sebagian besar mengalami penurunan tekanan darah, dan diastole post-test yaitu 14 responden $(53,8 \%)$ sebagian besar tekanan darah

tetap

Tabel 4 hasil uji T-Test skala perubahan tekanan darah $(\mathrm{mmHg})$ sesudah diberikan terapi musik klasik jawa pada kelompok subjek.

\begin{tabular}{llll}
\hline $\mathrm{N}$ & Hasil Hitung Paired T-Test & Mean & Sig. (2-tailed) \\
$\mathrm{o}$ & & & \\
\hline 1. & Sistole & $153 \mathrm{mmHg}$ &, 006 \\
& Pre-Test & $146 \mathrm{mmHg}$ & \\
& Post-Test & $101 \mathrm{mmHg}$ &, 002 \\
2. & Diastole & $97 \mathrm{mmHg}$ & \\
& Pre-Test & &
\end{tabular}

(Sumber: Data primer, 2017).

Dari tabel diatas dapat diketahui bahwa dengan menggunakan uji statistic Paired T-Test diperoleh mean sistol pre-test $153 \mathrm{mmHg}$, Post-test $147 \mathrm{mmHg}$ dan diastole pre-test $101 \mathrm{mmHg}$, post-test $97 \mathrm{mmHg}$. Dan diperoleh nilai $\mathrm{p}$ value systole $=0,006(\mathrm{p}<$ $0,05)$ dan $p$ value diastole $=0,002(p<0,05)$ maka H0 ditolak H1 diterima, artinya ada pengaruh terapi musik klasik jawa terhadap penurunan tekanan darah pada lansiahipertensi di UPT Panti Werdha Mojopahit Mojokerto.

\section{PEMBAHASAN}

Sebelum diberi terapi musik klasik jawa, tekanan darah responden rata-rata sistole $153 \mathrm{mmHg}$ dan diastole $101 \mathrm{mmHg}$ jauh lebih tinggi dari pada setelah diberikan terapi musik klasik jawa yaitu sistole 146 $\mathrm{mmHg}$ dan diastole $97 \mathrm{mmHg}$.

Tekanan darah tinggi atau hiprertensi merupakan peningkatan tekanan darah tekanan darah secara terus menerus sehingga melebihi batas normal dimana tekanan sistoliknya di atas $140 \mathrm{mmHg}$ dan tekanan 
diastoliknya di atas $90 \mathrm{mmHg}$. Hipertensi adalah keadaan ketika seseorang mengalami peningkatan tekanan darah di atas normal atau kronis dalam waktu yang lama. Hipertensi merupakan kelainan yang sulit diketahui oleh tubuh kita (Sylvia, 2009).

Hipertensi pada lansia bisa disebabkan hilangnya elastisitas pada pembuluh darah, selain itu, stress juga dapat mengakibatkan peningkatan tekanan darah pada lansia. Stres merupakan respon tubuh yang sifatnya nonspesifik terhadap setiap tuntutan beban atasnya. Terdapat beberapa jenis penyakit yang berhubungan dengan stres yang dialami seseorang, di antaranya hipertensi (Finda, 2012).

Menurut pendapat peneliti sesuai fakta dan teori yang ada, hipertensi yang dialami lansia di UPT Panti Werdha Mojopahit Mojokerto disebabkan karena stress. Hal ini disebabkan karena berpisah dengan anggota keluarganya atau jarang dikunjungi oleh keluarga. Selain itu juga disebabkan oleh suasana Panti yang tidak sama dengan rumahnya yang mengharuskan lansia beradaptasi kembali sehingga terjadi stress. Stress dapat dikurangi dengan mendengarkan musik, musik klasik jawa merupakan musik yang cocok untuk lansia.

Berdasarkan data setelah diberikan terapi musik klasik jawa menunjukkan bahwa tekanan darah responden pre-test systole 10 responden $(38,5 \%)$ dan diastole 11 responden $(42,3 \%)$ hampir setengahnya mengalami tekanan darah 160/100 mmhg. tekanan darah post test yaitu systole 14 responden $(53,8 \%)$ dan 12 responden $(46,2 \%)$ hampir setengahnya mempunyai tekanan darah 140/90 mmhg.

Terapi musik musik klasik jawa identik dengan tempo yang lamban, serta memiliki karakteristik yang lembut dan santai, mampu memperdalam dan memperkuat pernapasan, sehingga memungkinkan pikiran menjadi tenang. Laju pernapasan yang lebih dalam atau lebih lambat sangat baik, menimbulkan ketenangan, kendali emosi, dan pemikiran yang lebih dalam, dan metabolisme yang lebih baik karena pernapasan bersifat ritmis, musik klasik yang musiknya lambat juga membuat detak jantung menjadi lambat, semakin lambat detak jantung, dalam suatu kisaran yang lebih lambat menciptakan tingkat stress dan ketegangan fisik yang lebih rendah. Selain itu, pada saat orang sedang rileks dan santai, otak akan memproduksi hormon serotonin dan endorfin yang menyebabkan seseorang merasa tenang, nyaman dan bahagia. Musik dengan tempo lamban, biasanya efektif untuk mengatasi stres dan kecemasan.

Menurut pendapat peneliti sesuai fakta dan teori yang ada, terapi musik klasik jawa sangat banyak sekali manfaatnya tidak hanya dapan menurunkan tekanan darah terapi musik juga dapat mengurangi stress, depresi dan mengurangi rasa sakit. Seperti stress yang dialami oleh lansia yang dikarenakan situasi dan kondisi panti yang tidak sama dengan rumahnya.

Dari hasil menggunakan uji statistic paired t-test diperoleh mean sistol pre-test $153 \mathrm{mmhg}$, post-test $146 \mathrm{mmhg}$ dan diastole pre-test $101 \mathrm{mmhg}$, post-test $97 \mathrm{mmhg}$. dan diperoleh nilai $\mathrm{p}$ value systole $=0,001(\mathrm{p}<$ $0,05)$ dan $\mathrm{p}$ value diastole $=0,002(\mathrm{p}<0,05)$ maka h0 ditolak h1 diterima, artinya ada pengaruh terapi musik klasik jawa terhadap penurunan tekanan darah pada lansia hipertensi di upt panti werdha mojopahit mojokerto. dan hal tersebut sesuai dengan tujuan dilakukan pemberian terapi musik klasik jawa kepada lansia yang mengalami tekanan darah tinggi adalah untuk mengetahui ada atau tidaknya pengaruh terapi musik klasik jawa terhadap penurunan tekanan darah pada lansia hipertensi di upt panti werdha mojopahit mojokerto, dan hasil penelitiannya menunjukan bahwa ada pengaruh.

Terapi musik adalah usaha meningkatkan kualitas fisik dan mental dengan rangsangan suara yang terdiri dari melodi, ritme, harmoni, timbre, bentuk dan gaya yang diorganisir sedemikian rupa hingga tercipta musik yang bermanfaat untuk kesehatan fisik dan menta. Musik yang menenangkan dapat membantu menurunkan hormon-hormon yang berhubungan dengan stress, mengaktifkan hormon endorphin alami yang berfungsi sebagai penghilang rasa sakit, mengalihkan perhatian dari rasa takut, tegang dan cemas, menimbulkan perasaan rileks, meredakan amarah dan meringankan perasaan tertekan.

Salah satu upaya agar tekanan darah lansia tetap dalam stabil adalah dengan cara mendengarkan musik, yakni musik klasik jawa. Dengan adanya rileksasi dengan musik 
klasik diharapkan mampu mengurangi stress lansia di UPT Panti Werdha Mojopahit Mojokerto yang dapat memicu tekanan darah lansia tinggi.

Hasil penelitian pada lansia yang berada didi UPT Panti Werdha Mojopahit Mojokerto, disimpulkan bahwa tekanan darah pada lansia yang diberikan terapi musik klasik jawa mengalami penurunan dibandingkan sebelum diberikan terapi musik klasik jawa. Ini menunjukkan bahwa terapi musik klasik jawa yang diberikan peneliti pada lansia ternyata dapat meringankan beban stress sehingga tekanan darah lansia menurun.

\section{KESIMPULAN DAN SARAN}

\section{KESIMPULAN}

1. Tekanan darah lansia sebelum diberikan terapi musik klasik jawa di UPT Panti Werdha Mojopahit Mojokerto hampir setengahnya mengalami tekanan darah $160 / 100 \mathrm{mmHg}$.

2. Tekanan darah lansia setelah diberikan terapi musik klasik jawa di UPT Panti Werdha Mojopahit Mojokerto sebagian besar mengalami penurunan.

3. Ada pengaruh terapi musik klasik jawa terhadap penurunan tekanan darah pada Lansia.

SARAN

a. Bagi Responden

Diharapkan agar dapat melakukan terapi musik klasik jawa secara rutin sebagai salah satu terapi non-farmakologi hipertensi sehingga dapat membantu menurunkan tekanan darah pada lansia hipertensi terutama lansia hipertensi yang ada di UPT Panti Werdha Mojopahit Mojokerto dengan durasi 20-30 menit dalam sehari dengan posisi rileks.

b. Bagi tenaga kesehatan

Diharapkan kepada tenaga kesehatan lebih aktif memberikan informasi kepada masyarakat yang mengalami hipertensi tentang manfaat dari pemberian terapi musik klasik dimana salah satunya adalah dapat menurunkan tekanan darah.

c. Bagi Tempat Penelitian

Diharapkan terapi musik klasik jawa ini bisa digunakan untuk merencanakan program yang lebih efektif dalam menurunkan tekanan darah pada lansia hipertensi di UPT Panti Werdha Mojopahit Mojokerto. d. Bagi lansia hipertensi

Diharapkan terapi musik klasik jawa ini bisa digunakan sebagai terapi non-farmakologi dalam upaya menurunkan tekanan darah bagi lansia yang menderita hipertensi.

\section{DAFTAR PUSTAKA}

Amariana Finda,(2012) Hubungan Antara Stres Dengan Kejadian Hipertensi Pada Lansia Di Shelter Dongkelsari Desa Wukirsari Kecamatan Cangkringan Kabupaten Sleman Provinsi Daerah Istimewa Yogyakarta, http://thesis.umy.ac.id/datapublik/t2 3417.pdf diakses tanggal 6 jjanuari 2017.

Campbell, D. (2001). Efek mozart memanfaatkan kekuatan musik untuk mempertajam pikiran, meningkatkan kreativitas, dan menyehatkan tubuh. Jakarta: PT Gramedia Utama.

Dian Natalina. (2013) Terapi Musik Bidang Keperawatan. Jakarta. Mitra Wacana Media.

Dinkes Jombang. 2010. Data Hipertensi di Jombang.

http://www.jombangkab.go.id/. Diakses 24/02/2011.

IHA.2010. Indonesia Hypnosis Assosiation. http://www.hipnoterapi.asia/terapi_ musik.htm.

Mucci, R. dan Mucci, K. 2002. The Healing Sound of Music. Jakarta. PT GramediaPustaka Umum.

Sylvia. 2009. Diet Sehat Untuk Penyakit Asam Urat, Diabetes, Hipertensi dan Stroke. Yogyakarta. A-Plus Books. 